\title{
BMJ Open Implementation of robotic devices in nursing care. Barriers and facilitators: an integrative review
}

\author{
Ricarda Servaty (D , , ${ }^{1,2}$ Annalena Kersten, ${ }^{3}$ Kirsten Brukamp, ${ }^{3}$ Ralph Möhler, ${ }^{4}$ \\ Martin Mueller ${ }^{1}$
}

To cite: Servaty $R$, Kersten A, Brukamp K, et al. Implementation of robotic devices in nursing care. Barriers and facilitators: an integrative review. BMJ Open 2020;10:e038650. doi:10.1136/ bmjopen-2020-038650

- Prepublication history for this paper is available online. To view these files, please visit the journal online (http://dx.doi org/10.1136/bmjopen-2020038650).

Received 18 March 2020 Revised 11 August 2020 Accepted 18 August 2020

\section{Check for updates}

C Author(s) (or their employer(s)) 2020. Re-use permitted under CC BY-NC. No commercial re-use. See rights and permissions. Published by BMJ.

${ }^{1}$ Faculty of Applied Health and Social Sciences, Technical University of Applied Sciences, Rosenheim, Germany ${ }^{2}$ Institute for Medical Information Processing, Biometry, and Epidemiology, LudwigMaximilians-Universitaet, Muenchen, Germany

${ }^{3}$ Protestant University of Applied Sciences, Ludwigsburg, Germany

${ }^{4}$ School of Public Health, Universitat Bielefeld, Bielefeld, Germany

\section{Correspondence to} Ricarda Servaty; ricarda.servaty@th-rosenheim. de

\section{ABSTRACT}

Background Robots in healthcare are gaining increasing attention; however, their implementation is challenging due to the complexity of both interventions themselves and the contexts in which they are implemented. The objective of this integrative review is to identify barriers to and facilitators of the implementation of robotic systems in nursing.

Methods Articles published from 2002 to 2019 reporting on projects to implement robotic devices in nursing care were searched on Medline (via PubMed), CINAHL and databases on funded research projects (Community Research and Development Information Services and Technische Informationsbibliothek) and in journals for robotic research in November 2017 and July 2019 for an update. No restrictions regarding study designs were imposed. All included articles underwent quality assessments with design-specific critical appraisal tools. Barriers to and facilitators of implementation were classified using the Context and Implementation of Complex Interventions framework. Results After removing all duplicates, the search revealed 11204 studies, of which 17 met the inclusion criteria and were included in the synthesis. The majority of the studies dealt with the implementation of robots designed to support individuals, either living at home or in nursing homes $(n=11)$. The studies were conducted in Europe, the USA and New Zealand and were carried out in nursing homes, individual living environments, hospital units and laboratories. The quality of reporting and quality of evidence were low in most studies. The most frequently reported barriers were in socioeconomic and ethical domains and were within the implementation outcomes domain. The most frequently reported facilitators were related to the sociocultural context, implementation process and implementation strategies. Discussion This review identified barriers to and facilitators of the implementation of robotic devices in nursing within different dimensions. The results serve as a basis for the development of suitable implementation strategies to reduce potential barriers and promote the integration of elements to facilitate implementation. PROSPERO registration number CRD42018073486.

\section{BACKGROUND}

The development and application of robotics in healthcare has received much attention in

\section{Strengths and limitations of this study}

- This integrative review allows us to synthesise results from studies with different designs and methodologies within the topic of robotics in nursing.

- It demonstrates in a systematic manner which barriers and facilitators have previously played roles in the implementation of robotics in nursing in research.

- The results summarise the state of research and will help to inform the development of adequate implementation strategies of robotic systems in nursing.

- Results have to be interpreted cautiously due to the quality assessment of included articles, which was rather low.

- Comparisons between studies are hard to make due to the variety of research designs.

recent years as a possible answer to the demographic, epidemiological and economic challenges to healthcare systems ${ }^{1-3}$ despite the lack of robust evidence on the topic. ${ }^{4-6}$ Robotics in healthcare can have many different manifestations. We refer to the classification based on the areas of use. ${ }^{3}$ Rehabilitation robots are training devices and tools for movement performance, mobility and independence that are used to support physical functioning of individuals. Robots to support (healthcare) professionals are developed to relieve staff in terms of time or physical burden or provide information. Robots to support individuals (at home) are developed to support older individuals in maintaining their independence in activities of daily living or seek to facilitate their participation in social life. ${ }^{3-8}$ The boundaries between the areas of application are somewhat fluid, and some robots have various functions.

Evidence regarding the fulfilment of users' expectations is still scarce. ${ }^{5910}$ One likely explanation of why robotic systems, which may work as expected in laboratory settings, have failed to show their feasibility, acceptance or effectiveness in practice might be 
that the complexity of their implementation has been underestimated, neglected or insufficiently addressed in research. The implementation of a robotic system in nursing care must be seen as a complex intervention due to the number of involved stakeholders and their behaviours, the variability and number of outcomes and various interacting components. ${ }^{11}$ Therefore, the process of development, evaluation and implementation should follow established frameworks, such as guidance from the Medical Research Council. ${ }^{11}$ The Medical Research Council framework was developed to provide methodological recommendations for researchers (to choose suitable methods), funders of research (to understand the limitations of evaluation design) and users of the framework to assess the available evidence with regard to practical and methodological restrictions. ${ }^{11}$

An important preparatory aspect of the process of developing complex interventions is the identification of barriers and facilitators for the translation or implementation of innovations into practice. This knowledge should be used to create appropriate implementation strategies and to rule out approaches that are likely to fail. This could ultimately increase the likelihood of developing interventions that effectively address patientrelevant outcomes. ${ }^{12}$

Thus, the objective of this integrative review is to identify facilitators or barriers to the implementation of robotics in nursing care.

\section{METHODS}

An integrative review allows researchers to synthesise results from studies with different designs and methodologies (experimental and non-experimental). Empirical and theoretical work on a specific topic can be combined. To draw conclusions that allow for increased understanding of a phenomenon, the integrative review method can be used as a guide to summarise and analyse the literature. While this review focuses on studies translating research into practice, the review method enables the inclusion of reports on ongoing or prospective research. ${ }^{13-15}$

\section{Search strategy}

We carried out a systematic search in November 2017 and an update in July 2019. We searched four databases: Medline (via PubMed), CINAHL, Community Research and Development Information Services (CORDIS) and Technische Informationsbibliothek (TIB). The TIB is the world's largest library specialised in science and technology literature and offers access to a wide range of resources. CORDIS aims to optimise the use of research results of publicly funded projects and provides access to research reports that are difficult to obtain; it is maintained by the European Commission. To increase the chance of identifying relevant studies, four additional specific journals were searched: International Journal of Social Robotics, Journal of Robotics, International Journal of Robotics Research and Robotics and Autonomous Systems. A combination of two groups of keywords were used: (1) the broad term 'nursing' with all possible synonyms and (2) search terms to find robotic interventions that have been implemented in patient care. A combination of Medical Subject Headings terms with free text words was used. After an initial search in PubMed, the search string was adapted corresponding to all other databases and journals (see online supplemental material). In addition, backward citation tracking was conducted.

\section{Inclusion and exclusion criteria}

We included all types of study designs (qualitative, quantitative and mixed methods) as well as systematic reviews. The main inclusion criterion was the reported application and implementation of robotic technologies or similar technologies in inpatient or outpatient care settings for personal care or by nurses. Furthermore, we included research that investigated staff attitudes towards such systems, their motives and barriers to introduction. Studies in the German or English language published between 2002 and July 2019 were eligible for inclusion. We excluded studies that reported the use of robotics in surgical procedures or diagnostics that solely described clinical outcomes due to robotics or brain-computer interfaces.

\section{Data extraction and quality assessment}

All titles and abstracts of the identified articles were screened for eligibility by two independent researchers. For data extraction, a form with two sections was developed and piloted. The first section comprised general information, that is, study authors, year, country of origin, study design and detailed characteristics of the intervention (classification of the robot, ${ }^{3}$ summary of the description of implementation and reported barriers and facilitators). The second section contained intervention details, including the aim, underlying problem, setting, target group, intervention delivery methods and kinds of material used (based on the template for intervention description and replication). ${ }^{16}$ Data on facilitators of and barriers to the implementation of robotic systems were categorised using the context, implementation and setting dimensions of the Context and Implementation of Complex Interventions framework. This framework facilitates 'structured and comprehensive conceptualisation and assessment of context and implementation of complex health interventions'. ${ }^{17}$ The context and implementation dimensions include various subdomains. The context dimension comprises geographical, epidemiological, sociocultural, socioeconomic, ethical, political and legal domains. Within the implementation dimension, barriers and facilitators are categorised into the domains of theory, process, strategies, agents and outcomes. All three dimensions can interact with each other. ${ }^{17}$ For greater clarity, only barriers and facilitators that were reported in at least two studies are reported; all others are available on request. The data were analysed and synthesised based on the integrative review methodology: 
data from primary sources were converted into themes, assigned to systematic categories based on the Context and Implementation of Complex Interventions framework $^{17}$ and, finally, summarised. ${ }^{15}$

For quality assessment, we used design-specific critical appraisal tools: mixed-method and quantitative studies were appraised using the Mixed Methods Appraisal Tool, which was developed for the critical appraisal of mixed study reviews (reviews that include different study designs). ${ }^{18}$ Qualitative studies and systematic reviews were screened using the respective Critical Appraisal Skills Programme. ${ }^{1920}$ For the quality assessment of case reports, the Joanna Briggs Institute checklist for case reports was used. ${ }^{21}$ We decided to include any study irrespective of the results of the quality assessment because of the small amount of empirical information in this field. In addition, descriptive studies with methodological limitations may also provide useful information about barriers and facilitators. The results of the quality assessment are given for each study. We used Covidence ${ }^{22}$ to perform the study selection.

\section{Patient and public involvement}

There was no need to involve patients or members of the general public in the development and design of this integrative review.

\section{RESULTS}

After deduplication, we identified 11204 citations, and 17 studies met the inclusion criteria. A detailed overview of the study selection is displayed in figure 1 .

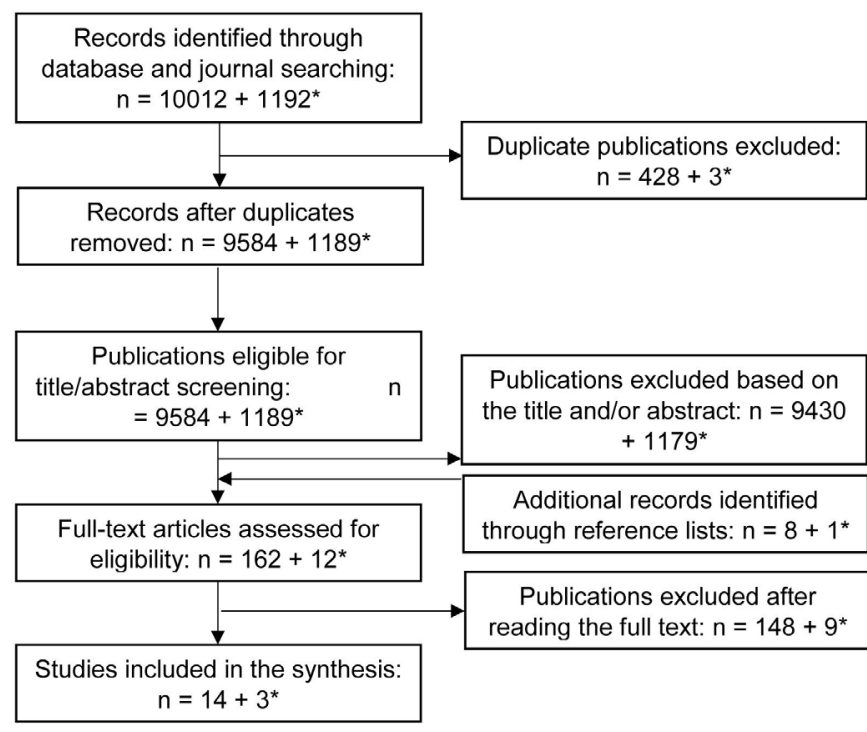

Figure 1 Preferred Reporting Items for Systematic Reviews and Meta-Analyses flow chart. Adapted from Moher et al. ${ }^{52}$ *Search update including articles from 21 November 2017 to 5 July 2019. Search conducted on 5 July 2019.

\section{Characteristics of the included articles}

We included six quantitative, five mixed-method and five qualitative studies and one systematic review. Seven studies were conducted in individual living environments, five were conducted in nursing homes, three were conducted in hospital units and two were conducted under laboratory conditions (living lab). The majority of the studies $(71 \%)$ were conducted in European countries, the USA and New Zealand. Most of the studies investigated the implementation of robots primarily designed to support individuals, either living at home or at nursing homes, ${ }^{23-33}$ or healthcare personnel. ${ }^{26}{ }^{34-38}$ Two robots had multiple functions to support both patients and healthcare personnel. ${ }^{26} 38$ Table 1 shows the characteristics of the studies in detail.

\section{Quality of the included articles}

The quality appraisal revealed that all studies had clear research questions or objectives, and the collected data were appropriate to address the research question. The two case reports ${ }^{24}{ }^{30}$ indicated sufficient quality. However, the reporting in the included studies often lacked transparency, so many quality appraisal dimensions could not be assessed. Additionally, it was often unclear whether an ethics committee reviewed the study. ${ }^{2425} 28343739$ Table 2 summarises the quality appraisal results. Detailed results are available on request.

\section{Factors influencing implementation}

We categorised the barriers and facilitators that were reported in individual studies according to the dimensions of the Context and Implementation of Complex Interventions framework. Barriers were most frequently assigned to the implementation outcomes $(n=10)$, socioeconomic $(n=8)$ and ethical $(n=8)$ domains. Facilitators were most frequently related to the sociocultural domain $(n=14)$, implementation process $(n=9)$, implementation strategies $(n=7)$ and epidemiological domain $(n=6)$ (table 3).

\section{Facilitators}

\section{Context}

Adapting robot functions to the needs of users was reported as a facilitator in the epidemiology subdomain (eg, communication patterns could be adjusted to a senior user group or healthcare personnel). ${ }^{232426283135}$ Social-cultural facilitators included individuals' overall positive attitudes towards technology, ${ }^{36}{ }^{38}$ the acceptance of end users 24273133353839 and positive feelings towards the device. ${ }^{27} 3032333536$ In contrast to non-acceptance, which was identified as a barrier, acceptance was reported to facilitate implementation. ${ }^{24} 28$ 31-35 39 Again, several factors had positive influences on acceptance: the design of the robot, ${ }^{33}$ the characteristics of the robot itself (eg, a machine with human traits), ${ }^{24}$ users' higher levels of computer experience, ${ }^{29} 31$ training of healthcare staff users, understanding of the abilities and actions of the robot, ${ }^{24}$ perceived improvement of quality of care, ${ }^{34}$ 


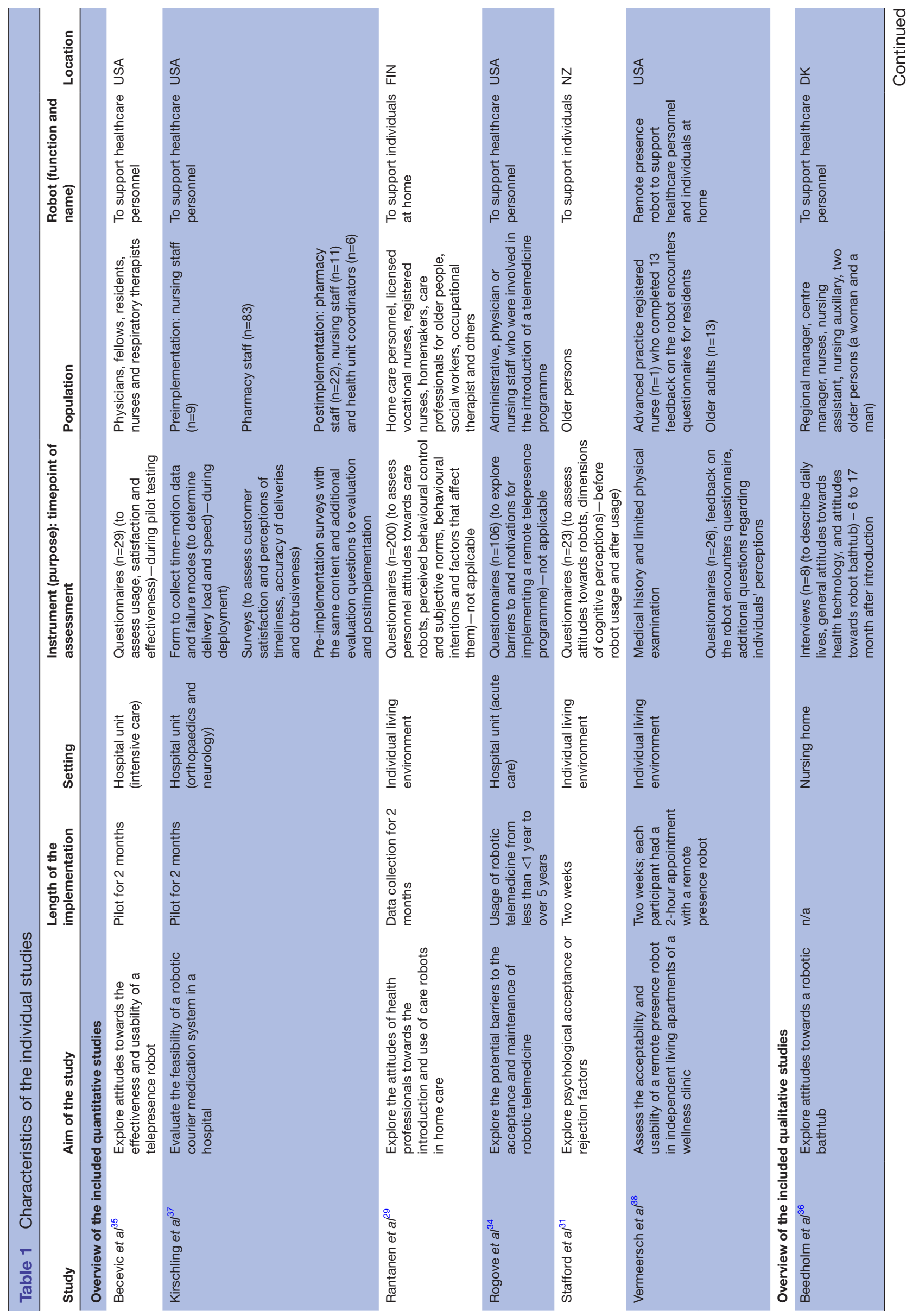




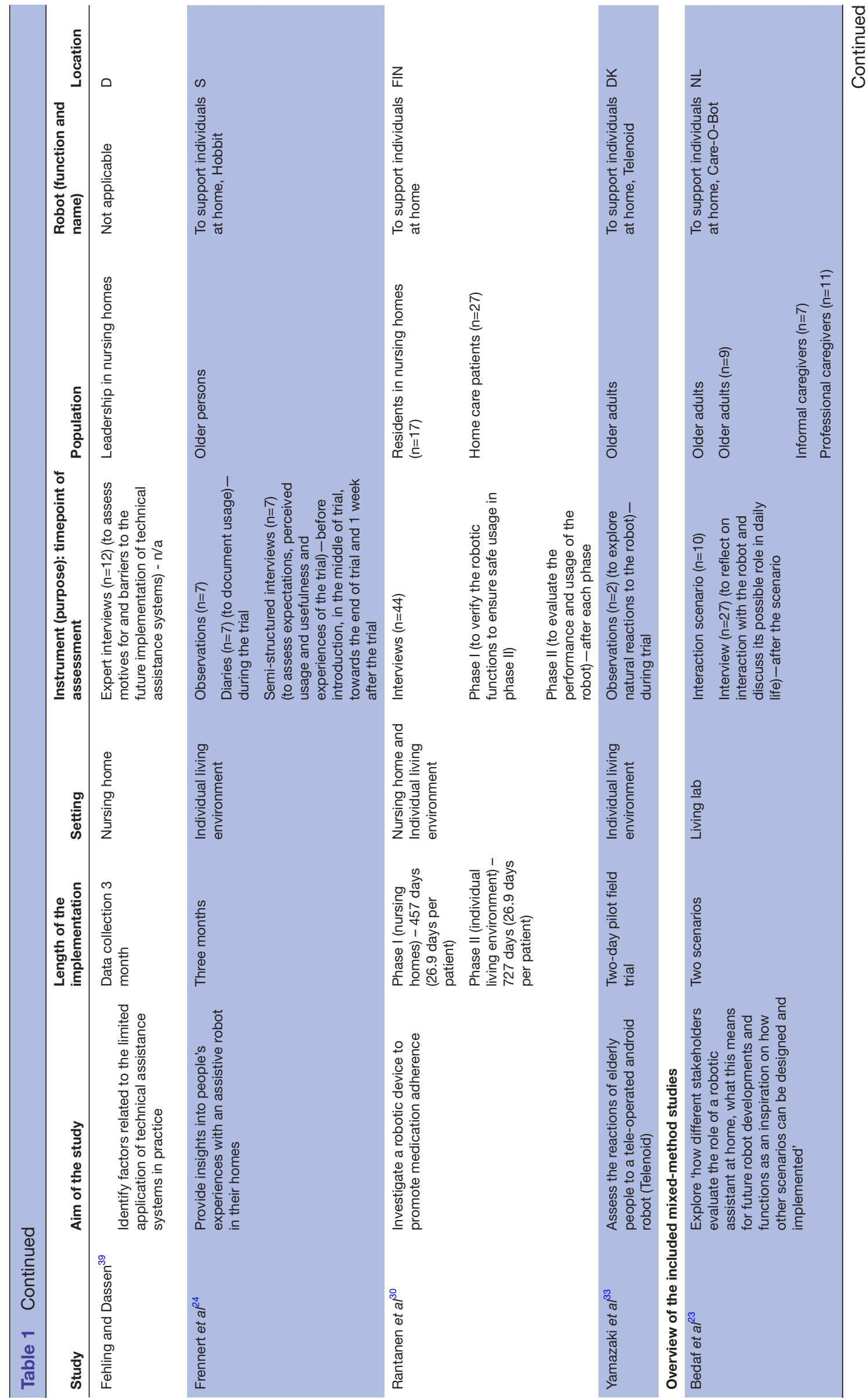




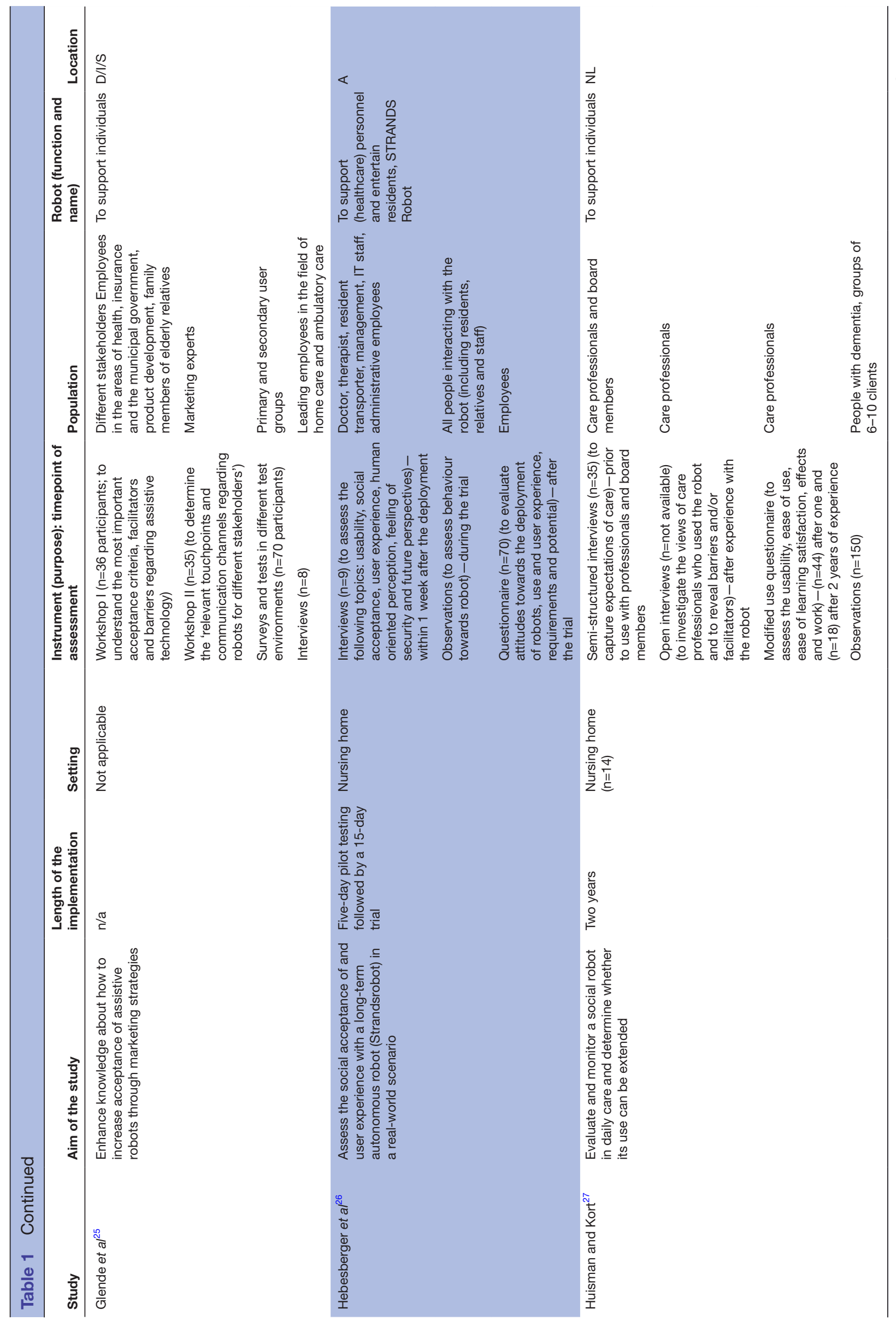




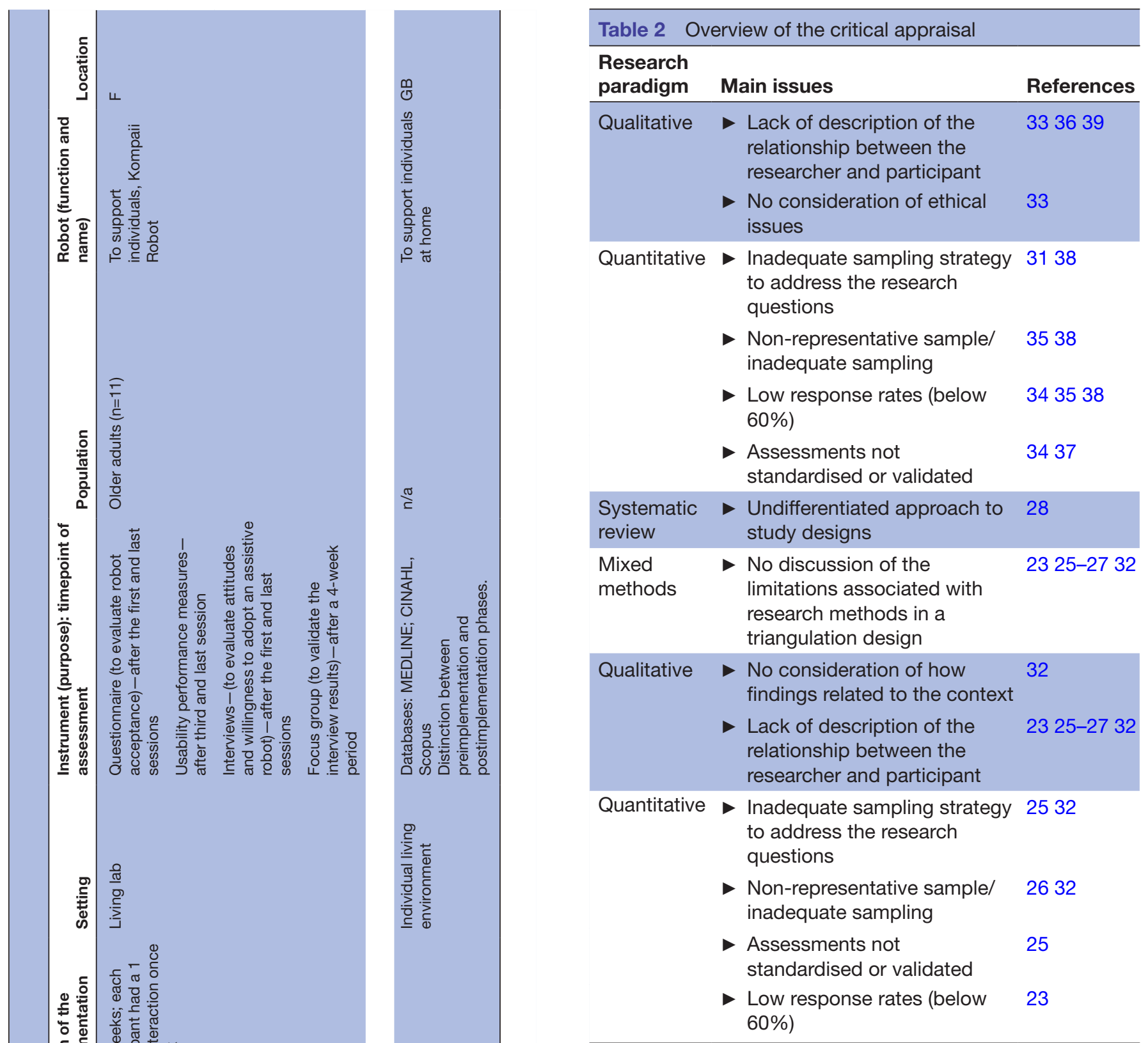

perceived usefulness of the robot, social influence from relatives, culturally specific attitudes towards robots, perceived increased independence ${ }^{28}$ and intentions to use the robot when becoming dependent. ${ }^{32}$ Positive feelings towards the robotic device, including curiousness, satisfaction, enthusiasm and confidence, further facilitated the implementation process. ${ }^{30} 323536$ Safe operation of the device was seen as an ethical facilitator. ${ }^{28} 30$

\section{Implementation}

One facilitator of the implementation process was the active involvement of healthcare personnel, who are intended users of the device, in the development. ${ }^{35} 3638$ Furthermore, studies of the use of robots in their intendent environments instead of living lab situations and detailed training and information about the device, such as implementation strategies, were identified as 


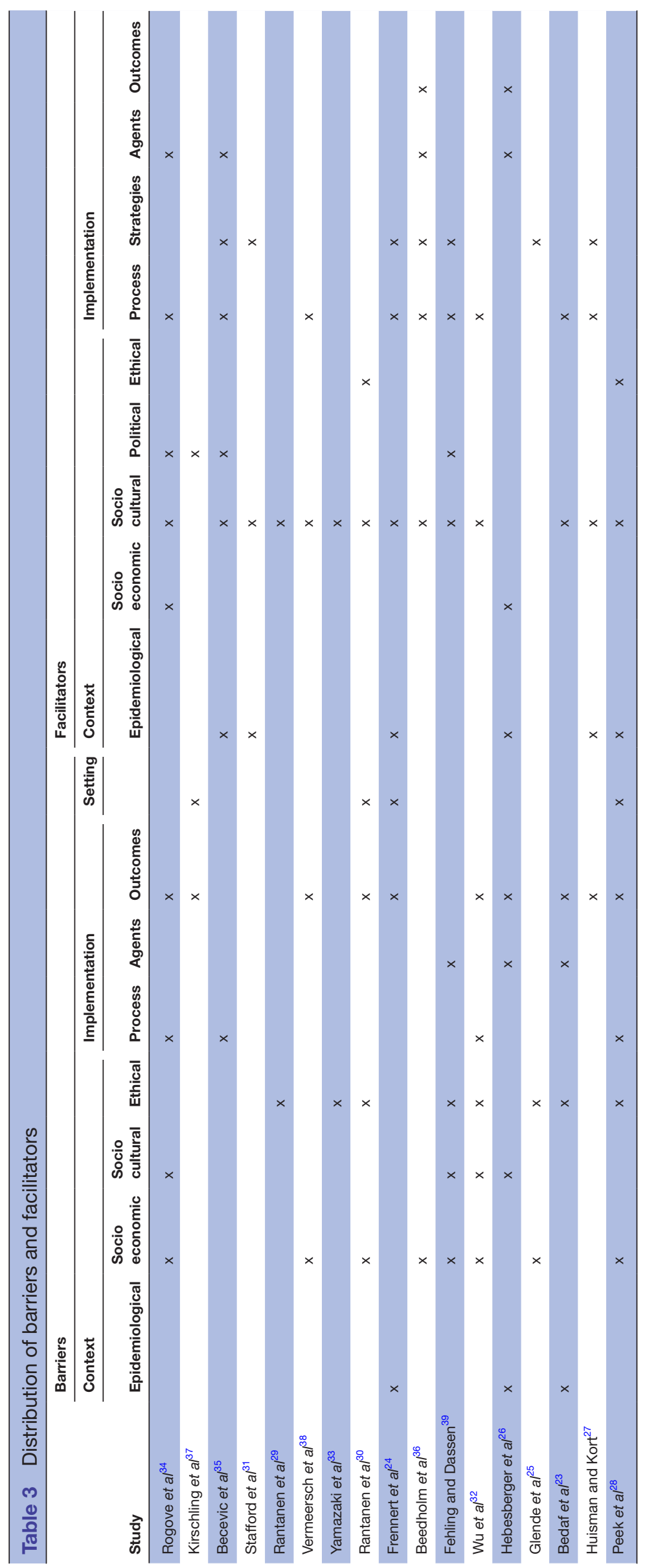

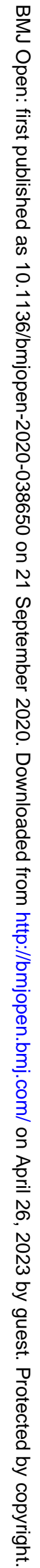


facilitators. $^{24} 25 \quad 27 \quad 31 \quad 35-37 \quad 39$ A consideration of robot technology as a source of support for healthcare personnel $^{263436}$ and a clear identification of roles, responsibilities and expectations ${ }^{35} 36$ were mentioned as facilitators of implementation agents.

\section{Barriers}

Context

Different user groups (including older adults, healthcare staff and managing staff) were worried about the high acquisition and maintenance costs of the robotic device, especially when there were more inexpensive alternatives (socioeconomic). ${ }^{2528303234363839}$ Additionally, unclear reimbursement situations were considered a barrier. ${ }^{34} 39$ The most frequently reported sociocultural barrier was non-acceptance from end users, which was reported to be associated with several factors. Older persons did not consider themselves potential users of assistive robots due to their current remaining independence, concern that usage of an assistive robot could lead to dependence, unfamiliarity with technologies, views of robots as a local threat and concerns about loss of control. ${ }^{26} 3234$ Age, high workload and qualification level of health professionals were described as additional factors relevant to acceptance. $^{32} 3439$ Ethical issues included the fear that personal human interaction would be replaced by action carried out by robots, ${ }^{30} 33$ the fear of decreased social contact, ${ }^{232529} 32$ patients' stigmatisation as being frail and dependent when using robotic devices, ${ }^{25} 28$ the fear of the dehumanisation of society, ${ }^{29} 3239$ privacy issues (eg, invasion of privacy, risk of surveillance, feelings of being followed and watched and low data security) 25283239 and the fear that the robots compromise capabilities and thus have negative effects on health. ${ }^{2528} 32$

\section{Implementation}

Within the domain of implementation agents, the fear that robots would replace staff emerged. ${ }^{232639}$ The main barriers to implementation outcomes were reports that actual abilities did not meet expectations ${ }^{24} 2838$ and technical barriers that were experienced during implementation (eg, malfunctions and miscommunication between the machine and user). ${ }^{23} 263032343738$

\section{Setting}

Barriers within the setting domain included sound issues (eg, fear of noise or loud sounds). ${ }^{2430}$ The robotic device not being adapted to the intended environment (eg, it was too large, or movement pattern did not fit in the setting) and the technology failing in certain locations were seen as barriers as well. ${ }^{2428} 37$

\section{DISCUSSION}

The overall aim of this review was to describe barriers to and facilitators of implementing robotic systems in nursing care to gain a better understanding of what is needed to successfully implement robotic systems in nursing.

\section{Barriers}

Barriers to implementation were most frequently associated with implementation outcomes, socioeconomic and ethical domains, whereas facilitators were predominantly within the sociocultural, implementation process, implementation strategies and epidemiological domains. However, overall, study quality was low, and implementation during pretests, pilot or evaluation studies or in practice was not comprehensively reported. Therefore, the results must be interpreted with caution and in light of the quality of evidence.

An important barrier to implementing robotic systems is the high costs of most systems, which make them unaffordable both for individuals and for institutions. ${ }^{3}$ It is still unclear and must be discussed at societal and political levels whether these costs can be covered by health insurance or federal social care systems. However, a serious discussion about reimbursement policies needs more information, in particular about the clinical effectiveness and cost-effectiveness of robotic systems based on high-quality systematic research that takes into account the complexity of interventions and follows established methodological guidelines, such as the Medical Research Council framework. None of the included studies used such frameworks.

The adoption of robotic systems in real-life scenarios crucially depends on their acceptance. ${ }^{40} 41$ Other researchers identified several variables that influence acceptance: age, gender, needs, previous experience with technology/robots, cognitive ability and education, culture and role of healthcare professionals. Negative attitudes towards robots negatively affect uptake, ${ }^{42} 43$ which is in line with our findings.

Closely related to the topic of acceptance are ethical barriers towards implementation. The risk of isolation and reduction in social contact, a loss of control and privacy issues have been reported in the literature. ${ }^{44} 45$ Additionally, the lack of reliability of technical devices has already been investigated. ${ }^{3}$ Those ethical barriers must be carefully considered during implementation in pilot studies as well as in effectiveness studies. There is already a demand for a standardised ethics code, which could play a major role in upcoming funding opportunities. ${ }^{46}$

The fear of healthcare professionals being replaced by robots is a major barrier for implementation. Although there is a broad societal understanding that robotic systems are not intended to replace personal interaction in health and social care, these fears have to be taken seriously in any phase of research. ${ }^{474}$ The implementation of innovations is difficult when the actual outcomes do not meet users' expectations. To overcome this barrier, discussions about possible functions and limitations should start early and follow an iterative process to involve individual perceptions and to moderate expectations. ${ }^{49}$ 
A lack of confidence in the safety of a device itself and the need for external experts for system setup or programming and operation have been criticised by previous research. However, most studies reported on projects that were still in the development stage using systems that were not fully functional. ${ }^{3}$ Future studies must investigate whether these issues persist or whether further developments are able to adequately address user experience and safety perception. Further research must also be conducted on the identified environmental barriers, such as the overall noise level or spatial arrangement.

\section{Facilitators}

In health and social care, different stakeholders with very different requirements may interact with robotic systems. ${ }^{50}$ To address these different perspectives, a detailed, comprehensive and tailored needs assessment must be carried out, which might ensure meaningful implementation. The need for such assessment is effectively paraphrased in guidelines for user integration in ambient assisted living projects: 'Determining actual user needs instead of merely guessing or generalising can make the difference between a real innovation for users or simply an interesting technical development for the shelf ${ }^{51}$ Users should be more involved in the development process and receive adequate training and information prior to implementation.

\section{Strengths and limitations}

This review has some limitations. First, the quality of the included studies is rather low, and all results must therefore be interpreted cautiously. Second, the inclusion of all research designs makes comparisons between studies difficult. However, we aimed to comprehensively cover and summarise the state of research to inform the development of appropriate strategies for the implementation of robotic systems in nursing. Thoroughly developed integrative reviews are known to have the potential to facilitate the development of evidence-based practice. ${ }^{15}$

\section{CONCLUSIONS}

This review summarises potential barriers to and facilitators of implementing robotic systems in nursing, which were identified in the dimensions of the Context and Implementation of Complex Interventions framework. Future research on robotics in nursing must account for the complexity of interventions and make use of rigorous research designs which are adequate for the actual development stage. The findings of the current review may help to develop adequate implementation strategies. Such detailed implementation strategies are needed to allow the transparent and reproducible implementation of robotic systems in pilot and feasibility studies, which provide the basis for developing high-quality randomised controlled trials that can lead to a well-informed discussion regarding the use of robotics in nursing among patients, healthcare practitioners, politicians and the public.

Acknowledgements The authors would like to thank Lisa Pfadenhauer, PhD for helping them interpret the Context and Implementation of Complex Interventions framework.

Contributors MM and RS conceptualised the study. RS developed the search strategy. RS and AK independently screened the titles and abstracts, assessed the eligibility of all identified publications for inclusion, and performed data extraction and quality assessment. MM was consulted in case of conflicts. RM was a major contributor to methodological questions. RS and MM drafted the manuscript. All other authors (AK, RM and KB) made significant contributions to content-related questions and read and modified drafts. All authors read and approved the final manuscript.

Funding This work was carried out as part of the 'MobIPaR' project, which is funded by the Federal Ministry of Education and Research (funding numbers 16 SV7733 (Rosenheim) and 16 SV7732 (Ludwigsburg)). Support was also provided by the Bavarian Academic Forum (BayWISS)—Doctoral Consortium 'Health Research', and funding was provided by the Bavarian State Ministry of Science and the Arts.

Competing interests None declared.

Patient consent for publication Not required.

Provenance and peer review Not commissioned; externally peer reviewed.

Data availability statement Data are available on reasonable request. Detailed results of quality assessment and an overview of all barriers and facilitators are available on reasonable request. All requests regarding data should be directed to martin.mueller@th-rosenheim.de.

Open access This is an open access article distributed in accordance with the Creative Commons Attribution Non Commercial (CC BY-NC 4.0) license, which permits others to distribute, remix, adapt, build upon this work non-commercially, and license their derivative works on different terms, provided the original work is properly cited, appropriate credit is given, any changes made indicated, and the use is non-commercial. See: http://creativecommons.org/licenses/by-nc/4.0/.

ORCID iD

Ricarda Servaty http://orcid.org/0000-0002-0534-0296

\section{REFERENCES}

1 BMBF. Technik zum mensch bringen: Projekte. Available: https:// www.technik-zum-menschen-bringen.de/projekte?b_start:int=0

2 Butter M, Rensma A, van Boxsel J, et al. Robotics for healthcare: final report, 2008.

3 Klein B, Graf B, Schlömer IF, et al. Robotik in Der Gesundheitswirtschaft: Einsatzfelder und Potenziale. Heidelberg: medhochzwei, 2018.

4 Kachouie R, Sedighadeli S, Khosla R, et al. Socially assistive robots in elderly care: a Mixed-Method systematic literature review. Int J Hum Comput Interact 2014;30:369-93.

5 Buhtz C, Paulicke D, Hirt J, et al. Robotische systeme Zur pflegerischen Versorgung Im häuslichen Umfeld: ein scoping review. Zeitschrift für Evidenz, Fortbildung und Qualität im Gesundheitswesen 2018;137:1-8.

6 Broekens J, Heerink M, Rosendal H. Assistive social robots in elderly care: a review. Gerontechnology 2009;8:94-103.

7 Okamura A, Mataric M, Christensen H. Medical and health-care robotics. IEEE Robot Autom Mag 2010;17:26-37.

8 Becker H, Rüegsegger A, Scheermesser M, et al. Robotik in Betreuung und Gesundheitsversorgung. Zürich: vdf Hochschulverlag AG an der ETH, 2013: 22. 62-4.

9 Abdi J, Al-Hindawi A, $\mathrm{Ng} \mathrm{T}$, et al. Scoping review on the use of socially assistive robot technology in elderly care. BMJ Open 2018;8:e018815.

10 Pu L, Moyle W, Jones C, et al. The effectiveness of social robots for older adults: a systematic review and meta-analysis of randomized controlled studies. United States, 2019.

11 Craig P, Dieppe P, Macintyre S, et al. Developing and evaluating complex interventions: the new medical research council guidance. BMJ 2008;337:a1655.

12 Richards DA, Hallberg RI. Complex interventions in health: an overview of methods. London, New York: Routledge, 2015. 
13 Tricco AC, Lillie E, Zarin W, et al. A scoping review on the conduct and reporting of scoping reviews. BMC Med Res Methodol 2016;16:15.

14 Sutton A, Clowes M, Preston L, et al. Meeting the review family: exploring review types and associated information retrieval requirements. Health Info Libr J 2019;36:202-22.

15 Whittemore $\mathrm{R}$, Knafl K. The integrative review: updated methodology. J Adv Nurs 2005;52:546-53.

16 Hoffmann TC, Glasziou PP, Boutron I, et al. Better reporting of interventions: template for intervention description and replication (TIDieR) checklist and guide. BMJ 2014;348:g1687.

17 Pfadenhauer LM, Gerhardus A, Mozygemba K, et al. Making sense of complexity in context and implementation: the context and implementation of complex interventions $(\mathrm{CICl})$ framework. Implement Sci 2017;12:21.

18 Pluye P, Hong QN. Combining the power of stories and the power of numbers: mixed methods research and mixed studies reviews. Annu Rev Public Health 2014;35:29-45.

19 Critical Appraisal Skills Programme. CASP (qualitative) checklist. Available: https://casp-uk.net/wp-content/uploads/2018/01/CASPQualitative-Checklist.pdf [Accessed 5 May 2018].

20 Critical Appraisal Skills Programme. CASP (systematic review) checklist. Available: https://casp-uk.net/wp-content/uploads/2018/ 01/CASP-Systematic-Review-Checklist.pdf [Accessed 5 May 2018].

21 Moola S, Munn Z, Tufanaru C. Chapter 7: systematic reviews of etiology and risk. In: Joanna Briggs Institute Reviewer's Manual, 2017.

22 Veritas Health Innovation. Covidence systematic review software. Melbourne, Australia.

23 Bedaf S, Marti P, Amirabdollahian F, et al. A multi-perspective evaluation of a service robot for seniors: the voice of different stakeholders. Disabil Rehabil Assist Technol 2018;13:592-9.

24 Frennert S, Eftring H, Östlund B. Case report. Inter J Soc Robot 2017;9:401-15.

25 Glende S, Conrad I, Krezdorn L, et al. Increasing the acceptance of assistive robots for older people through marketing strategies based on Stakeholder needs. Int J Soc Robot 2016;8:355-69.

26 Hebesberger D, Koertner T, Gisinger C, et al. A long-term autonomous robot at a care hospital. Int J Soc Robot 2017;9:417-29.

27 Huisman C, Kort H. Two-Year use of care robot Zora in Dutch nursing homes: an evaluation study. Health Care 2019;7

28 Peek STM, Wouters EJM, van Hoof J, et al. Factors influencing acceptance of technology for aging in place: a systematic review. Int $J$ Med Inform 2014;83:235-48.

29 Rantanen T, Lehto P, Vuorinen P, et al. The adoption of care robots in home care-A survey on the attitudes of Finnish home care personnel. J Clin Nurs 2018;27:1846-59.

30 Rantanen P, Parkkari T, Leikola S, et al. An in-home advanced robotic system to manage elderly home-care patients' medications: a pilot safety and usability study. Clin Ther 2017;39:1054-61.

31 Stafford RQ, MacDonald BA, Jayawardena C, et al. Does the robot have a mind? mind perception and attitudes towards robots predict use of an eldercare robot. Int J Soc Robot 2014;6:17-32.

$32 \mathrm{Wu} \mathrm{Y-H}$, Wrobel J, Cornuet M, et al. Acceptance of an assistive robot in older adults: a mixed-method study of human-robot interaction over a 1-month period in the living lab setting. Clin Interv Aging 2014;9:801-11.
33 Yamazaki R, Nishio S, Ishiguro H, et al. Acceptability of a teleoperated android by senior citizens in Danish Society. Int J Soc Robot 2014;6:429-42.

34 Rogove HJ, McArthur D, Demaerschalk BM, et al. Barriers to telemedicine: survey of current users in acute care units. Telemed J E Health 2012;18:48-53.

35 Becevic M, Clarke MA, Alnijoumi MM, et al. Robotic telepresence in a medical intensive care unit-clinicians' perceptions. Perspect Health Inf Manag 2015;12:1c.

36 Beedholm K, Frederiksen K, Frederiksen A-MS, et al. Attitudes to a robot bathtub in Danish elder care. Nur Health Sci 2015;17:280-6.

37 Kirschling TE, Rough SS, Ludwig BC. Determining the feasibility of robotic courier medication delivery in a hospital setting. Am J Health Syst Pharm 2009;66:1754-62.

38 Vermeersch P, Sampsel DD, Kleman C. Acceptability and usability of a telepresence robot for geriatric primary care: a pilot. Geriatr Nurs 2015;36:234-8.

39 Fehling P, Dassen T. Motive und Hürden bei Der Etablierung technischer Assistenzsysteme in Pflegeheimen.

40 Riek LD. Healthcare robotics. Commun ACM 2017;60:68-78.

41 Broadbent E, Stafford R, MacDonald B. Acceptance of healthcare robots for the older population: review and future directions. Int J Soc Robot 2009;1:319-30.

42 Keyworth C, Hart J, Armitage CJ, et al. What maximizes the effectiveness and implementation of technology-based interventions to support healthcare professional practice? A systematic literature review. BMC Med Inform Decis Mak 2018;18:93.

43 Nomura T, Kanda T, Suzuki T. Experimental investigation into influence of negative attitudes toward robots on human-robot interaction. Al Soc 2006;20:138-50.

44 Sharkey A, Sharkey N. Granny and the robots: ethical issues in robot care for the elderly. Ethics Inf Technol 2012;14:27-40.

45 Kreis J. Umsorgen, überwachen, unterhalten - sind Pflegeroboter ethisch vertretbar? In: Bendel O, ed. Pflegeroboter. Wiesbaden: Springer Gabler, 2018: 213-28.

46 Mühlberger S. Regeln für Roboter. Available: https://www.mpg.de/ 12290850/regeln-fuer-roboter [Accessed 23 Jun 2020].

47 Gisinger C. Pflegeroboter aus Sicht der Geriatrie. In: Bendel O, ed. Pflegeroboter. Wiesbaden: Springer Gabler, 2018: 113-24.

48 Früh M, Gasser A. Erfahrungen aus dem Einsatz von Pflegerobotern für Menschen im Alter. In: Bendel O, ed. Pflegeroboter. Wiesbaden: Springer Gabler, 2018: 37-62.

49 Kehl C. Wege zu verantwortungsvoller Forschung und Entwicklung im Bereich der Pflegerobotik: Die ambivalente Rolle der Ethik. In: Bendel O, ed. Pflegeroboter. Wiesbaden: Springer Gabler, 2018: 141-60.

50 Becker H. Robotik in der Gesundheitsversorgung: Hoffnungen, Berfürchtungen und Akzeptanz aus Sicht der Nutzerinnen und Nutzer. In: Bendel O, ed. Pflegeroboter. Wiesbaden: Springer Gabler, 2018: 229-67.

51 Nedopil C, Schauber C, Glende S. Guideline the art and joy of user integration in AAL projects, 2013.

52 Moher D, Liberati A, Tetzlaff J, et al. Preferred reporting items for systematic reviews and meta-analyses: the PRISMA statement. PLoS Med 2009;6:e1000097. 